\title{
Looping and Attachment in Early Childhood Education: How the Applications of Epigenetics Demand a Change
}

\section{Elena Nitecki 1}

\begin{abstract}
Increasing focus on the quality of childcare and Pre-K is calling attention to the circumstances of childcare and impact on the child's social and emotional health, specifically in terms of attachment. The early childhood profession recognizes that consistency in caregiving is essential for the child's attachment. Looping, the practice of keeping a group of children with the same teacher for more than year, has the potential to provide that consistency that is critical for attachment. The field of epigenetics and its compelling findings concerning attachment demand a second look at looping and how it can be implemented to maintain attachment, which is critical to the child's physical, cognitive, and emotional health now and in the future. This case study, conducted at a preschool that practices looping, examines the benefits and challenges of looping through the lens of applied epigenetics.
\end{abstract}

\section{Keywords: Case Study; Early Childhood Education; Looping; Attachment}

The education of our youngest children, ages 0-5, has come to the forefront. The consistently high number of children in childcare and the current expansion of preschool programs through the Universal Pre-Kindergarten movement only focuses more attention on the importance of early education. As preschool and childcare are being recognized as the first stage in the formal educational system in this country, it is imperative to examine the circumstances of childcare and impact on the child's social and emotional health, specifically in terms of attachment. Institutions of higher education are involved in research around these topics and preparing future educators, but there exists little emphasis on the impact of attachment or how the traditional early childhood classroom can be re-conceptualized.

A child's experience in childcare or preschool represents the first experience away from home with an alternate caregiver. Some children experience this transition as young as 6 weeks old, before attachment is fully developed. Consistency in caregiving is essential for the child's attachment (Bowlby, 1988; Goldberg, Muir \& Kerr 2013; NAEYC, 2015). Looping, the practice of keeping a group of children with the same teacher for more than a year, has the potential to provide a consistent caregiver during the young child's critical period of attachment and emotional development. Looping, the classroom practice that builds on attachment and continuity of care, has been examined in the literature, but not practiced in a widespread fashion in the United States, nor given adequate attention in teacher preparation programs in colleges and universities (Lab at Brown University, 1997). The field of epigenetics and its compelling findings in regard to attachment demand a second look at looping and how it can be implemented to maintain attachment, which is critical to the child's physical, cognitive, and emotional health now and in the future. This case study examines the benefits and challenges of looping through the lens of the

1 Department of Early Childhood \& Childhood Education, Mercy College, 555 Broadway, Dobbs Ferry, NY 10522.

enitecki@mercy.edu. 
burgeoning field of epigenetics, which deserves attention from practitioners in the field, as well as those in higher education who are responsible for training the next generation of teachers.

\section{Looping in Early Childhood Education}

Looping, also known as "continuous learning," "continuity of care," "continuous progress," or "persisting groups," is the practice of keeping the same caregiver or teacher with a group of children for two to three years (Grant, Johnson and Richardson, 1996; Lab at Brown University, 1997). This practice originated in Waldorf schools in Europe over a century ago and is still quite common in Europe. There have been scattered applications in the United States, most notably Deborah Meier in New York City during the 1970s and in private Waldorf and Reggio Emilia Schools. In the 1990s, there was a rediscovery and interest in looping in American schools, but overall, has it has been practiced sparingly in the United States (Lab at Brown University, 1997). Looping usually groups children of the same age, but has been used in multi-age classrooms, especially in Montessori schools. The practice of looping stresses long-term relationships, so students of the same age group remain with the same teacher for more than one school year, while multi-age classrooms may have a different teacher year after year (Hanson, 1995; Hegde \& Cassidy, 2004). Many schools considering a multi-age program view looping as a first step. This study will focus on a school that practices both looping and multi-age grouping, both intentionally and as a consequence of the circumstances. Overall, looping has been underutilized in the United States, despite the compelling evidence of its benefits.

The literature on looping, which is largely qualitative, supports the process and identifies several advantages for students, parents, and teachers. The most obvious and powerful benefit is the existence of consistent and long-term relationships between students, teachers, and parents (Brebner et. al, 2015; Chirichillo, 2001; Lab at Brown University, 1997; Thomas, 2014). Hegde and Cassidy (2004) examined parent and teacher perspectives on looping, finding that the advantages were clear: stability and continuity of care, ease in transition year to year, anticipating children's needs, and increased parent friendships and networking. Looping provides children with additional time to build the trust and relationships on which much of children's learning depends (Haslinger, Kelly, \& O'Lare, 1996; Lincoln, 1997). Children develop stronger social bonds with their peers, are better able to resolve conflicts and are more skillful in working as team members to solve problems (Hanson, 1995). Looping can turn parents into supporters and promotes stronger bonding between parents and teachers (Hegde \& Cassidy, 2004). In short, the practice of looping "exemplifies the importance of bonding, attachment and security between a child and a teacher and increased communication and trust between parents and teachers" (Hegde \& Cassidy, 2004, p.133).

In addition to relationships, looping has academic benefits. The practice essentially adds an extra month of teaching and learning time during the second year when the typical transitional period at the beginning of the year is virtually unnecessary (Hanson, 1995; Burke, 1996). There is less time spent learning names, becoming familiar with rules and procedures, and assessing the child academically and developmentally. In addition, teacher knowledge about a child's strengths and weaknesses increases in a way that is impossible to achieve in a single year (Lab at Brown 1997). This deeper knowledge about students allows teachers to anticipate behavior, resulting in fewer behavioral challenges (Minkel, 2015). With looping, a teacher can implement a more coherent instructional plan appropriate to the child's development (Grant, et al., 1996). Teachers report that moving a level ahead with their students promotes teacher innovation and keeps

Journal of the Scholarship of Teaching and Learning, Vol. 17, No. 2, April 2017.

josotl.indiana.edu 
teachers motivated (Hegde \& Cassidy, 2004). A teacher who practices looping describes the transformation (Minkel, 2015, para. 41-42):

Every time I loop, I see boys who were angry and mean become

calm and gentle. I see once-timid girls become confident and

assertive. I also see a community of 25 students become more

than the sum of its parts. I witness that annual alchemy of personalities, interests, and talents working its gradual magic. The children

become better readers, writers, thinkers, artists, scientists, and mathematicians, and I become a better teacher.

The case against looping, and perhaps the reasons why the practice has not become widespread in the United States, has few points, but they are compelling (Hegde \& Cassidy, 2004; Thomas, 2014). The persistence of negative relationships over the course of two or three years is a major impediment. If any of the relationships between teacher, parents, and students are strained, it could just become worse with time. Teachers also report that adapting to range of grade levels can be challenging, especially when they prefer a certain age group (Hegde \& Cassidy, 2004). These challenges are dependent upon individual preferences and personalities and perhaps can be dealt with as exceptions to the general rule. The logistical challenge to looping, especially in early childhood education, is the high rate of turnover among teachers, which is more than $30 \%$ for all teaching staff in early childhood setting (Porter, 2012). Administrators considering the use of looping must be certain that the teacher will be at the school for at least two years, which is not always a given. As a result, looping exists in the shadows of the educational system, both in schools and in college programs that prepare teachers. In fact, a recent study found that teachers report an overall lack of knowledge and information regarding the practice of looping in early childhood public education (Thomas, 2014).

This study focuses on the relational benefits of looping, specifically in terms of attachment for young children, ages 0-5. Looping is especially important for young children, whose social emotional foundation is being built through attachments with parents and caregivers. Looping is consistent with the NAEYC philosophy, specifically, that children's healthy brain development is improved by attachment and a sense of belonging, and fostering positive relationships with children is a goal (Jacobs, 2012). A secure attachment between the caregiver and relates to other areas of development, areas such as social- emotional development, cognitive development and language development (Bowlby, 1988; Goldberg, Muir \& Kerr, 2013; Hegde and Cassidy, 2004; Murgatroyd \& Spengler, 2011). Previous studies, such as Bowlby's landmark attachment theory (1953, 1988) and Hegde \& Cassidy's study (2004), alluded to the relationship between attachment, which is promoted through looping, and healthy development, but we now know this as a certainty, thanks to the recent discoveries in epigenetics. These recent scientific findings (Dube, et. al, 2003; Lieberman \& Knorr, 2007; Murgatroyd \& Spengler, 2011; Scaer, 2005; Thomson, 2007) provide evidence linking early experiences and stressors to physical and emotional problems and cite a solid base of attachment as a preventative measure. Even with these compelling findings, "current childcare center policies and practices for transitioning children in and out of classrooms seem to be at odds with current research on attachment, continuity, and the development of peer relationships" (Groot, 2010, p. 153). The future does not look any different, since teacher preparation programs in institutions of higher education do little to bring these findings to the forefront of their curriculum. 


\section{How the Field of Epigenetics Has Magnified the Importance of Attachment}

It is commonly accepted that a major benefit of looping is the opportunity for continuous relationships between teachers, children, and families. This is especially important for young children, ages 0-5, whose attachments are still forming. In fact, early attachment theory (Bowlby 1953, 1988) defined the critical attachment period as the first two years of life. Many young children are in childcare centers well before two years old. Not only is the attachment with the parent disrupted, but the possibility for forming an alternate attachment with a teacher is not likely in childcare centers with a high staff turnover rate and thus, no continuity of caregiver (Porter, 2012). Recent findings in the field of epigenetics call attention to the importance of attachment and demand a change in how childcare is managed for our youngest children.

Epigenetics is the "newly emerging branch of biology that deals with the effects of external influences on gene expression... at the biological level, this is where nature and nurture become indistinguishable" (Karr-Morse and Wiley, 2012, p. 152). To non-scientists, this means that environmental forces can alter DNA, as well as current and future health. Karr-Morse and Wiley (2012) examine the explosion of epigenetic literature in recent years, focusing on "the role of early emotions in shaping the organization of the central nervous, endocrine, and immune systems and the physical mechanisms that render children particularly vulnerable to the effects of fear and trauma" (p. xvi). Persistent patterns of negative emotions, like fear, in young children, particularly under 5 years old, renders the developing nervous system more vulnerable to trauma and disease now and even later in life. The effects of this trauma has been linked to physical diseases like cancer, diabetes, heart disease, and asthma, as well as psychological issues such as addiction, emotional health, depression, schizophrenia, Alzheimer's, and autism (Karr-Morse \& Wiley, 2012).

How, exactly, do negative emotions as a young child result in these serious disorders? When a child feels fear, ephemeral sensations we call 'feelings,' our emotions, fuel the stress response in our brains, causing changes in the autonomic nervous system and physical changes (Karr-Morse \& Wiley, 2012, p.19). Sometimes, this fear is so extreme or persistent and is accompanied by a state of perceived helplessness it becomes traumatic. Often times, diseases result from chronic perceptions of helplessness and hopelessness added to toxic stress, leading to the overstimulation of the autonomic nervous system (Murgatroyd \& Spengler, 2011). All children experience a series of "little traumas" - not cataclysmic events - but they have the same effect, setting up a lifelong course of systemic dysregulation (Scaer, 2005). These "little traumas" begin before birth, including stress in utero related to the mother's undernutrition, malnutrition, and toxins in the womb (Karr-Morse \& Wiley, 2012, p. 66). Even a mother's stress during pregnancy results in "maternal cortisol directly transported across placenta and enters fetal system through the exchange of blood" (p. 65). It is clear that prenatal stressors have implications in terms of early brain development.

Upon birth, there are more possibilities for these "little traumas," including prematurity and the resulting physical strain on the infant's body, difficult or traumatic births, and intrusive medical intervention, like forceps and induction. "From the last trimester of gestation to age two, we experience the most rapid brain growth of our lifetime. This growth is not entirely symmetrical. The emotional right brain undergoes a growth spurt in the first two years of life... and dominated development through the end of the child's third year, when spoken language begins to flourish and stimulate growth on the left side" (Karr-Morse \& Wiley, 2012, p. 209). Thus, these newborns are especially sensitive to effects on their social and emotional development. Thomson (2007)

Journal of the Scholarship of Teaching and Learning, Vol. 17, No. 2, April 2017.

josotl.indiana.edu 
notes that much of what we consider as problems resulting from neonatal experience is actually a reflection of life in the womb.

During infancy, toddlerhood, and leading up to age five, there is an "emotional vulnerability of the immature system that is so overlooked in our culture" (Karr-Morse \& Wiley, 2012 , p. 97). The widely held opinion about young children is that trauma experienced at a young age is "erased over time, lost in the fog of early experience" (p. 92). This is simply not true. The brains of young children are particularly tuned to both positive and negative emotions in surroundings. Lieberman notes that "one of the most important findings over the last 30 years is that there is no such thing as a baby not noticing what is happening" (cited in Karr-Morse \& Wiley, 2012, p. 103).

It follows that to prevent the negative effects of stress on the child's developing and fragile system, there should be a solid, consistent, base of attachment. The importance of attachment is not new, going back to foundational studies conducted by Bowlby (1953, 1988). However, recent findings based on the implications of epigenetics amplify the call to prioritize the child's need for attachment, especially in settings outside of the home. The main caregivers are responsible for the "blueprint for baby's own emotional regulations and future expectations of relationships" (KarrMorse \& Wiley, 2012, p. 98). In fact, inconsistent caregiving or early separation from a caregiver (in most cases the mother) is in fact a traumatic event, and has had negative effects (Karr-Morse \& Wiley, 2012). Lieberman (2007) defines trauma as anything that results in the disruption of the 'secure base' - essentially any experience that seriously disrupts the physical and emotional balance and security provided by the child's primary relationship with an adult, typically the mother."

The traumas that disrupt the secure base are numerous - ranging from abusive parents, depressed or emotionally distant parents, repeated medical intervention, adoption, foster care, divorce, death of a parent, absent parents, stress in the home, and yes, even child care. This is a controversial topic, but through this lens, leaving the consistent attachment of a parent to attend a center outside of the home is a "little trauma." As Karr-Morse and Wiley (2012) explain:

A securely attached baby who has been well attended by a sensitive and responsive caregiver may continue to cry and exhibit distress at separation from the mother, but by around six months of age will have about the same baseline cortisol levels in the alternative care setting as those at home. For insecurely attached children, by contrast, even minor emotional challenges raise cortisol levels (p. 112).

Certainly, childcare is not the villain. Out of home childcare is a crucial support for families - and one that is only increasing in need and use. It is a necessity, with $3 / 4$ mothers with children under six working 30+ hours a week (Karr-Morse \& Wiley, 2012, p. 121). The problem is how it is practiced and implemented has not caught up to what we know about what children need for optimal development. Childcare, what should be the foundation of our nation's educational system, still lacks the standards and public support it deserves and the education, training, and salaries of the childcare workers remain subpar (Porter, 2012). As a result, many children are being traumatized and re-traumatized by the gap between what we know and what we do (Karr-Morse \& Wiley, 2012). There are some troubling findings regarding how child care, particularly longer hours at a younger age, affects quality of attunement and attachment. More hours in child care 
correlate to higher rates of aggression among kindergarteners, more aggressive and disobedient behavior through grade 6 (Karr-Morse and Wiley, 2012). Although high quality care has some cognitive benefits at 54 months of age, quality - not quantity - produces constructive results (p. 116).

The main contribution of applied epigenetics to the discussion on childcare and early education is that attachment really matters, as Bowlby (1953) first recognized over a half-century ago. Early childhood trauma can lead to an array of negative health outcomes and behaviors, the effects of which can last a lifetime (Dube, et al., 2003; Murgatroyd \& Spengler, 2011). Of course, we cannot control the trauma, some horrific, that young children experience in their own homes, but secure attachment and positive relationships are critical to offset some of these negative influences. We have all had little traumas in our childhoods, but a strong remedy is "just one key relationship - just one person who is available to the child over time, who sees the [child] as valuable, and who communicates that feeling - can make all the difference in how later stress or trauma affect's the child's future" (Karr-Morse \& Wiley, 2012, p. 189). These key relationships are often found with teachers, the adults with whom children spend the most time outside of the home.

Perhaps, even if infants and toddlers did not have a positive attachment period, there is hope if there were a long-term relationship with a teacher in a childcare center or school that practices looping. Within the context of a safe, familiar environment with a steady caregiver, attachment can form, which leads to self-regulation, and ultimately maintaining physical, cognitive, and emotional health. "Because self-regulation begins with the physiological regulation of the infant by an adult and because the process is built into the baby's brain, and because it shapes behavior and health for a lifetime, attunement and secure attachment are among the most crucial skills to protect within our families" (Karr-Morse \& Wiley, 2012, p. 212). This process of gradually learned emotional connectedness to other people - or the failure of that process - begins with the family. However, with more families relying on childcare and some families with too many distractions and stressors, this responsibility falls on the childcare and early education institutions. It is time for us to recognize the important role that early educators play in facilitating and maintaining secure attachments, which generate stunning physical consequences that affect not only individual well-being but also familial, community, national and world health" (KarrMorse \& Wiley, 2012, p. 194). Looping is a first step in meeting this critical need for healthy attachment of our youngest children and should be part of the conversation in schools, private child care centers, preschools, colleges, and universities.

\section{A Case Study in Looping: Millcreek School}

Millcreek School (Note: the school and all personal names used are pseudonyms) is a private preschool located in the northeastern United States. Millcreek has a history of being familyoriented. A small group of friends who were trained abroad in Montessori methods founded the school eight years ago. Although there have been setbacks - namely, the untimely death of one of the founders, some contention between the remaining owners, and declining enrollment - the school has survived. Millcreek is private and financially supported through tuition. Although the tuition at Millcreek is among the lowest for Montessori schools in the region and comparable to other private preschools in the area, it is out of reach for many of the families in the county. Similar Montessori schools in the city have tuition three times the rate at Millcreek. Millcreek has not raised the tuition in four years and has a program in place to assist presently enrolled families under financial strain. Even so, enrollment has dropped from an all-time high of 38 children to a 
current low of 13 students. As a result, two teachers and an assistant have been laid off, and the school is operating with a restricted budget.

At the time of this study, the student body was composed of four females and nine males, ranging in age from 2.5 to 6 years old. Consistent with the Montessori model of multi-age grouping and the practice of looping, the children are grouped together with the same teachers in this tworoom school for the entire duration of their schooling, typically 2-3 years, even when the school had more enrollment and staff. The director manages the administrative aspects of the school on a part-time basis but is rarely on-site. There are three female teachers: one head teacher, Ms. Beth, who is Montessori-certified, and two part-time assistants, Ms. Sue (a parent) and Ms. Ann (a parent of a Millcreek graduate), both of whom have backgrounds in the field of Education and share the position as volunteer assistant.

Since Millcreek adheres to a specific curricular model, it is important to understand the classroom setting, which is quite distinct from other preschool curricula. The Montessori model is known for its emphasis on independent learning and a supportive community. The Montessori model is highly individualized and encourages independence, so children work at their own pace, which is a major benefit of multi-age grouping. Children choose their own "work," so they feel a sense of ownership and control over their learning. The materials are designed for a developmental progression in five areas of Montessori education: language, practical life, mathematics, sensorial, and geography/cultural studies (American Montessori Society, 2015). During the long "work" period (2-3 hours), the teacher interacts individually with children on their progress in various areas. The day also consists of group "circle time" and social time at recess and lunch. The Montessori program at Millcreek has impressive results. Last year, 90\% of the graduating preschoolers (4-5 year-olds) at Millcreek were already at a Kindergarten reading level or higher. Traditional academic skills are not the only focus of learning. Teachers emphasize the development of social and emotional skills and integrate themes of sustainability, active lifestyles, and healthy eating throughout the year. The well-rounded approach to learning considers the development of the whole child.

Most relevant to this study, the Montessori philosophy encourages social and emotional development and values relationships. Children begin at Millcreek at age 2.5 to 3 years old and stay with the same teacher and peers until leaving at age five or six. Because Millcreek exemplifies the practices of both looping and multi-age grouping, it is an interesting case study, especially in light of applied epigenetics research.

\section{Methodology}

The case study employs an inductive participatory action research approach to examine the implementation, benefits, and challenges associated with looping in a preschool setting. The case study as a qualitative method is appropriate for inductive, exploratory research that can then be used to formulate more specific questions or identify trends (Creswell, 2013; Yin, 2013). The case study is inductive since it begins with two general research questions: "How does this preschool program use looping? What are the benefits and challenges associated with looping, as viewed through the lens of applied epigenetics?"

During eight months of data collection, institutional background information and data were collected first. Then, interviews of the 3 teachers and 18 parents (at least one parent of each child) were conducted at the school, before and after school hours at the parents' convenience. (Interview Protocol is located in Appendix A). The focus of the interview was the parents' perceptions of their experiences at Millcreek, specifically their role as partners in their child's education and their Journal of the Scholarship of Teaching and Learning, Vol. 17, No. 2, April 2017.

josotl.indiana.edu 
observations of their own child's progress. Classroom observation occurred 48 times. In addition, observation included 12 family events and meetings outside of school hours. Observations were general at first, then focused more specifically, as coding themes emerged from the data. A memorandum of understanding between the school and researcher was approved, and IRB approval was obtained.

The particular qualitative approach utilized was participant observation, in which the researcher collected data on naturally occurring behaviors in their usual contexts, in this case, the daily interactions in the Millcreek school. Three forms of data were triangulated to establish themes: observations at the school, interviews with teachers and parents, and documents from the school and surrounding community, including demographic data and institutional records. The discussions from the interviews were audio recorded and transcribed. Observations were documented with the observer's notes. All data collection and analysis was personally conducted by the principal investigator. To assure consistency and trustworthiness, observation criteria was stipulated and a thoughtful set of questions was used with at least one parent of every child at Millcreek, ensuring diversity of perspectives and information-rich sampling. The qualitative data was then systematically coded and analyzed to find similar themes from all three sources: the institutional documentation, the interviews, and the observations. During the course of exploring this data, open coding was used to identify three general themes: how looping was implemented; the benefits; the challenges. Once these themes were established, axial coding was used to investigate the connections between the evidence and provide many sub-categories of these three themes. At the conclusion of data analysis, member checks were conducted with the teacher, the director, and most of the parents to ensure that the findings were sound and credible. The methodology of qualitative participant observation over eight months, as well as the interviews, allowed for a nuanced and detailed examination of the research question.

\section{Findings: How Looping Works, Benefits, and Challenges}

Millcreek teachers made a decision to practice looping when the school was established and had two classrooms. Now, with decreased enrollment, looping is practiced out of necessity. This is a small school with few teachers. Ms. Beth and her two assistants taught the one and only class in the school. Children started the program at about 3 years old and stayed with the same class and teachers until they were 5 or 6 years old. Of the 13 children involved in the study, 11 began at Millcreek between 2.5 and 3.5 years old and stayed for two or more years. Two students from this group stayed 3 years, as they completed the Kindergarten year at Millcreek. The other two students started later, only staying for one year before entering public school kindergarten. On average, this class of students stayed in a consistent setting with the same teachers for 2.4 years.

This is not to imply that over the course of these years the experience was the same for the students. The roles of the children changed over time. Younger children (2.5 to 4 years old) are welcomed and oriented into the program. There is a lot of observing older children and exploring. The older children (4 -6 years old) become the teachers and role models for the younger students. They have more responsibility and do more advanced "work" that builds upon the work of the first year.

A typical day at Millcreek began with parents bringing the children at 9:00a.m. The assistants took the children to find "work" while Ms. Beth talked with every parent. This drop-off time was a valuable opportunity for parent communication and did much to build the relationships between teacher and parents. Ms. Beth described this as "a necessary part of what we do in Montessori education. It also makes it much easier to bring up issues when you feel comfortable 
with the parents." Indeed, problems could be handled immediately, instead of waiting for a phone call or conference. The observations revealed many topics covered during these daily chats. Parents asked questions, updated the teacher on situations at home, and just chatted socially. Many conversations extended to topics beyond the classroom. Then, the class would join for morning circle between 9:30-9:45a.m. This was a time to welcome the children, do the calendar, and introduce new concepts or work for the day. Often, the older children would dominate the conversations, while the younger children watched or squirmed. From 9:45-12:00, the children were engaged in an extended work period. During this time, consistent with Montessori methods, the children were expected to choose their own work and initiate learning. Teachers would engage in individual "lessons" appropriate for their developmental level and in sequence with the Montessori planes of development. The younger children focused on basic lessons like practical life, pouring, sweeping, basic motoric skills, and fundamental numeric and phonetic concepts. The older children had more advanced lessons involving reading, operations, complex problemsolving, and exploration of new concepts. Often, an older child was observed approaching a struggling young child to model the work that s/he had already mastered. This type of peer learning reinforced what the teachers were doing. The remainder of the day consisted of lunch, another circle time with story read aloud, and outdoor exploration time until parents returned at 2:00p.m. Throughout the days, the growing level of comfort between the children and the teacher was obvious.

\section{Benefits of Building Relationships, Extended Learning, and Family Support}

Although the general category of "benefits," was a starting point in the research questions and initial data gathering, it soon became apparent that the benefits were complex and intertwined. One of the most notable benefits of looping is the consistent relationships with students and families over time. Hegde \& Cassidy (2004) found that "teachers felt that being with the children over time as their primary caregivers was essentially advantageous and beneficial to these young children. The continuity allowed these children to feel more secure and stable. Further, in many ways this led to building a more secure and a trustworthy relationship between the teacher and the children" (p. 134). There were many instances observed in which Ms. Beth's knowledge of the children and a trustworthy relationship was apparent. She explained that "getting to know the children during the first few months is important, but it doesn't end there. I watch how they grow and change over time. It helps to know the history of the child when we tackle new things." Indeed, the teachers spent a lot of time during the first few months of school simply observing the younger students to gain a sense of where they were developmentally. They built these relationships by taking the time to speak individually with every child about his/her work or interests. The relationships were visible with the older children. Ms. Beth often made references to the progress of the older children, like 5-year-old Esther when she completed the entire Hundred Board: "I remember when you were three and we counted to 10 together. Now look - you can go to 100 all by yourself!" This level of personal knowledge builds trust and consistency, which is essential for social and emotional development. Looping provides children with additional time to build the relationships on which much of children's learning depends (Haslinger, Kelly, \& O'Lare, 1996; Lincoln, 1997).

These relationships were especially important for children who were experiencing significant stress at home, as in one notable case. Leon was a 4-year-old boy who just started the school and had a severe speech delay. He was impulsive, and many children did not understand him, which often led to frustration. One day during his third month of school, he was particularly disruptive, and when redirected, he threw his work across the room and stomped away, refusing 
to rejoin the class activities. Ms. Beth told Leon's mother about the behavior and explained that she asked Leon to rejoin the class when he was ready and had a discussion with him about appropriate ways to "use his words" and handle his frustration. When Ms. Beth asked the mother if she ever saw this behavior at home, Leon's mother began sobbing, explaining that her husband was deployed to Iraq again and that she was "on her own" with Leon and her 7-year-old daughter, all while trying to work nights as a nurse. She was mentally and physically exhausted and had no energy to deal with Leon's behavior. This conversation, while emotional and painful, built much rapport and allowed Ms. Beth some valuable insight as to the cause of Leon's behavior. Leon's father, the disciplinarian of the family, was now absent, which negatively affected Leon, a significant stressor. Ms. Beth offered empathy and support to the family. She gave Leon's mother an idea of how she and the assistants handled Leon's behavior and encouraged her to try the same at home. Ms. Beth also connected Leon's mother with a babysitter who could help out so she could get some rest! The relationship between Leon's mother and Ms. Beth was strengthened considerably after this event and they could communicate openly about his behavior. In addition, the extra support lent by Ms. Beth went a long way to help Leon through the stress he was experiencing at home. Leon's behavior improved over the course of the next few months, despite the stress at home. This was an example of how the strong relationships built through with a consistent caregiver supported a child and family experiencing stress.

As demonstrated in Leon's case, strong relationships with parents and the children could prevent misbehavior. Ms. Beth and the assistants knew the children so well that they anticipated their behavior. For example, 4-year-old Jay, who was in his second year at Millcreek, was a busy, easily distracted and excitable child. Ms. Beth recognized this pattern and made sure that she did lessons with Jay earlier in the day, when he was more attentive, and made efforts to keep him away from another boy, who had a similar demeanor. In addition, the older children, who knew the rules and expectations, often reminded the younger students what to do. For example, observations revealed two older girls, who the teachers privately referred to as "mother hens," often redirected the younger children, showing them how to sit in circle, how to do their work, or even help with washing hands in the bathroom. This type of peer reinforcement of behavioral expectations reinforced the teacher's message. Indeed, behavioral issues were minimal by the third month of school and those presented were handled quickly and consistently. The level of negativity associated with handling misbehavior was remarkably low because there was a level of attachment and consistency already established between the students and teachers.

Another major benefit is extended learning for both the students and the teachers. In terms of teaching time, looping essentially adds an extra month of teaching/learning time during the second year when the typical transitional period at the beginning of the year is virtually unnecessary (Burke, 1996). The early year observations showed that the teachers started right in with the older children. In fact, one assistant teacher explained it like this: "In September, the focus is always getting the new or young kids on board with the routine and expectations in Montessori. Usually that is less than half of the class. The older kids, who were with us all of last year, just jump right in where they left off in June. It's great - they are so independent." This added academic benefit not only increases learning but builds up the child's confidence in his/her abilities, as learning is viewed as continuous.

It is not only the older children who have extended time to learn, but also the teachers. Teachers recognized another added benefit to looping, a personal benefit that working with a class over time promotes: innovation and professional growth. The teachers could not recycle projects and assignments year after year. Having the same students for two or more years required them to 
be creative in planning new work. Ms. Beth explained her system: "For each topic we cover, I have files with many project ideas. Every year, we do something different so the children experience something new each year. Maybe every 4-5 years, I will repeat a project, but this has forced me to stay creative." In addition to innovation, the teachers also benefit by working their skills in handling a range of ages and developmental expectations. One of the assistants new to the school stated, "I think I've become a better teacher this year, definitely better thinking fast on my feet. I've had to deal with 2-year-olds having potty accidents then turn around and help 5-yearolds sort out a sharing conflict. I pretty much feel ready to tackle any problem a toddler or kindergartener can bring." This kind of growth and learning on behalf of the children and the teachers contributed to a sense that everyone was learning together and had extra time to do so, because of foundation of a pre-existing relationship.

Parents also reaped the benefits of looping. Looping can turn parents into supporters and promotes stronger bonding between parents and teachers (Burke 1997; Hegde \& Cassidy, 2004). The parent involvement at Millcreek was quite strong, with every family contributing something to the school, whether it was time, supplies, or skills. The eight months of observation, specifically of the new parents at Millcreek, revealed that brief daily updates often evolved into multidimensional relationships. In fact, several parents characterized Ms. Beth as not only a teacher, but a friend by the end of the year. The parents overwhelmingly "love" Ms. Beth. As one parent described, "Beth is so special. She has the perfect preschool personality...bubbly and fun, but stern if need be." Ms. Beth made an effort with every parent, even those who were not as involved as others. At a summer "painting party," five families (including students and siblings), the director, and the teachers congregated to repaint the bookshelves, furniture, and walls. There was laughing, poking fun, and a real sense that "we were all here to fix up our school." This level of commitment is above average, even for preschool, where there is generally a much higher level of volunteering. When asked about this level of commitment, parents cited their relationship with the teachers and the school: "Millcreek is part of our life. [Our son] has been coming here since he was a baby and now he's a big boy." "Ms. Beth is just so much a part of our lives. We know her and trust her and want this school to succeed." Clearly, this level of commitment is rooted in strong relationships, which evolved from the attachment that the consistency that looping provides.

\section{Challenges of Practicality, Good Fit and Adaptation}

To be fair, the negative aspects of looping must be acknowledged. The main issues include: practicality, a good fit, and adaptation on the part of the student and the teacher, specifically, the possibility that students would not adapt to change in future grades, and teachers' ability or willingness to adapt to a range of age levels. At Millcreek, there was evidence of a few of these challenges.

The first and most popular complaint about looping is practicality. Millcreek is a small, private school with a dedicated teacher. Circumstances of low enrollment and intentional efforts were made in the decision to practice looping and multi-age grouping. Turnover was not a concern, so the anticipation of having the same teacher for more than a year is practical. This is not the case in every school, especially since the rate of turnover among preschool teachers is quite high (Porter, 2012).

Another challenge is achieving a good fit between teacher and student. If it is not a good match, for whatever reason, looping presents the unintended consequence of the persistence of negative relationships over years. Ms. Beth is well-liked, but there was one notable exception, the mother of 3-year-old Rose. This mother was extremely involved with the school; she started a Journal of the Scholarship of Teaching and Learning, Vol. 17, No. 2, April 2017.

josotl.indiana.edu 
parent gardening group and always volunteered. However, about six months into the school year, Rose was having difficulty staying focused and was easily frustrated. Ms. Beth noticed the behavior and asked her mother about routines at home, such as bedtime, eating patterns, and recent changes. Rose's mother asked for Ms. Beth's advice and admitted that she and her husband did not really have a set bedtime for Rose and often, she would stay up until 10:00 or 11:00 p.m. with them. The more Ms. Beth heard about Rose's home life, the more she realized that it was a very disorganized and chaotic environment for a 3-year-old child. Ms. Beth gently suggested ways to institute a routine and why it would benefit Rose. Her mother became very defensive, ended her involvement with the school, and pulled Rose out of school, opting to keep her home until the new school year began. A few weeks before ending her involvement with the school, Rose's mother said in an interview, "I know [Ms. Beth] means well and she is an awesome teacher, but she has no right butting into the way I raise my child." Ms. Beth was saddened by the family's decision and said, "It is not fair to Rose, and I am sorry they made that choice out of anger." Even though Rose's mother sought out Ms. Beth's suggestions on how to handle Rose's behavior, some parents are not open to such advice. In this case, Rose's mother perceived the parenting suggestions negatively, which had an unfortunate effect on Rose and the family's involvement with Millcreek. When asked about the possibility of leaving, Rose's mother said, "I just don't think I can handle this for two more years. Beth overstepped her boundaries and I am the parent." It can be expected that there may be friction between some parents and teachers. In a classroom that utilizes looping, the prospect of staying with the offending teacher for the rest of the year, let alone more than a year, can be troublesome for parents. Perhaps in a school with more than one classroom, there would be an option to move the child.

A last challenge is the notion of adaptation. The child, who has become accustomed to the same teacher over time, must someday face the adjustment to a new teacher. Within the infant and toddler age range, it has been noted that attachment and bonding are essential (Bowlby 1958, 1988; Burke, 1997; Goldberg, Muir \& Kerr, 2013). Children need the stability bonding and then can later adapt to new environments and teachers. By age five or six, children enter the transition into concrete operations and become more social. Most have secure attachments are able to adapt quite easily (Bowlby, 1988). In fact, Ms. Beth often asked parents how older siblings, who were Millcreek alumni, were doing. Parents reported in the interviews and to Ms. Beth that their children who entered Kindergarten or $1^{\text {st }}$ grade after Millcreek "adjusted so well" and "jumped right in with no fear." One parent, whose second child recently started public school reported, "She had a great transition into public school. I think Ms. Beth did such a great job of making her feel confident and smart that she was ready for anything. She needed those two years here to grow up, grow into herself, before facing the big school."

In addition to the child's ability to adapt, the teacher must adapt to teaching children of various age ranges. This was not an issue for Ms. Beth, who had a wide range of abilities with children ages 2.5 to 6 years old. She would often pull aside small groups of children with similar abilities and conduct mini-lessons or show new work appropriate to their level. Teachers in looped classrooms must not only be comfortable with the range in ages and abilities, but have time management skills that allow them to work with each group. The teacher's level of comfort with various age groups seems to be a matter of preference, but Ms. Beth and the assistants welcomed the challenges and opportunities of working within a multi-age classroom. This model is a cornerstone of the Montessori model. As Ms. Ann, one of the assistants, described it, "I love the different ages. It is like having a big family here, with big brothers and sisters teaching the younger ones. We [the teachers] get to watch them grow up over the course of a couple years and it's 
amazing. They come in as babies and leave us all grown up - and we can say that we were a part of that growth." This sense of achievement certainly seems to contribute to positive morale among the staff. To summarize, Table 1 outlines the specific benefits and challenges associated with looping at Millcreek.

\section{Table 1}

Summary of Benefits and Challenges of Looping, ages 2-5

\begin{tabular}{|l|l|}
\hline Specific Benefits & Specific Challenges \\
\hline $\begin{array}{l}\text { Teacher develops strong relationships with } \\
\text { children over time and development, which } \\
\text { has social-emotional and learning } \\
\text { implications. }\end{array}$ & $\begin{array}{l}\text { Practicality in schools with high staff } \\
\text { turnover. }\end{array}$ \\
\hline $\begin{array}{l}\text { Consistency of relationships allow for open } \\
\text { communication about stress at home }\end{array}$ & $\begin{array}{l}\text { Good fit between teacher and child or } \\
\text { persistence of negative relationships over } \\
\text { time. }\end{array}$ \\
\hline $\begin{array}{l}\text { Behavior problems are minimal because } \\
\text { teachers know what to expect from the } \\
\text { children. }\end{array}$ & $\begin{array}{l}\text { The child's ability to transition and adapt to } \\
\text { a new teacher/school after spending so long } \\
\text { with a familiar teacher. }\end{array}$ \\
\hline $\begin{array}{l}\text { Extended learning time for older students who } \\
\text { do not need transitional time at the beginning } \\
\text { of the year. }\end{array}$ & $\begin{array}{l}\text { The teacher's ability to adapt to new age } \\
\text { groups and the challenges each presents. }\end{array}$ \\
\hline $\begin{array}{l}\text { Teachers have opportunities for extended } \\
\text { learning by having to be innovative over the } \\
\text { years and adapt to different age groups. }\end{array}$ & \\
\hline $\begin{array}{l}\text { Parents develop bonds with teacher over time, } \\
\text { leading to more investment in the school, } \\
\text { volunteering, and support of learning at home. }\end{array}$ & \\
\hline
\end{tabular}

\section{Implications}

The case study at Millcreek is an excellent example of how looping works for this small school. In light of the recent applications of epigenetics and importance of fostering attachment during the early years, looping should be reconsidered as a way to build a meaningful foundation for young children, many of whom do not have such a foundation at home. Given the physical and mental health implications of stress on the developing brains of young children, we should be doing everything we can to build a foundation of secure attachment. "There is much we can do at any age to heal and reduce the cumulative toll of chronic fear and trauma on our health" (Karr-Morse \& Wiley, 2012, p. x.). The malleable early childhood years present a golden opportunity to prevent many problems that come as a result of stressors. This study represents an example of how research can shed light on an important, but neglected topic in the field of early childhood education. Although the case study presents limited empirical evidence to support consideration of children's social-emotional well-being in terms of relationships with the caregiving adults in out-of-home care, it is an attempt to bring attention to an important topic that institutions of higher education should be researching further and certainly including in their teacher preparation curriculum. 
Of course there are larger social changes that would help immensely, such as better education for parents about their critical role in the development of their child (Bowlby 1988; Dube, et al., 2003; Karr-Morse \& Wiley, 2012) and extending maternity leave so that parents have adequate time to properly bond with their babies (Karr-Morse \& Wiley 2012; Thompson, 2007), but let us focus our discussion on implications within the realm of education. The applications of epigenetics should raise awareness about the importance of a consistent caregiver, which is rare in the field of childcare, which has very low pay and high turnover (Porter, 2012). Perhaps efforts to raise the status and compensation in the field of early childhood education would result in more teachers like Ms. Beth, who stick with a school for years, providing a consistent teacher year after year. Only with a consistent teacher can looping be practiced (Laboratory at Brown University, 1997). A teacher with the same students over the course of two or three years can build a meaningful relationship with the students and their families. This is especially critical during the early years, infancy through Pre-K. The looping model would require the field of childcare and preschool to reconsider the teacher assigned to only one age group and demand that teachers extend outside of their comfort zones to adapt to the multi-age classroom. It is an undertaking, but well worth the effort, in terms of a child's overall development - academically, socially and emotionally. Only with attention and further research on this topic, which requires cooperation with institutions of higher education, can meaningful change occur.

As preschool becomes integrated with the standard school system in the United States through the Universal Pre-K movement, teachers, administrators, colleges, and universities should consider the potential of looping, especially in light of the findings in epigenetics, which define the malleable nature of the early brain and the critical role of attachment. Looping is one classroom practice that can do much to provide a consistent base of attachment and mitigate the negative effects of stressors that many young children experience.

\section{Appendix A: Interview Protocol for Families}

1. Background Information

a. How long has your child attended Millcreek?

b. Why did you choose this school for your child's first educational experience?

2. Perception of Relationships at the School

a. How would you describe your experience at Millcreek?

b. How do you perceive your child's experience? What are your observations of your child's progress?

c. How do you feel about your child being with the same teacher for more than a year?

d. What are the pros and cons of this approach?

e. How do you view your role as a partner in your child's education?

\section{References}

American Montessori Society. (2013). The Montessori classroom. Retrieved from http://www.amshq.org.

Brebner, C., Hammond, L., Schaumloffel, N., \& Lind, C. (2015). Using relationships as a tool: early childhood educators' perspectives of the child-caregiver relationship in a childcare setting. Early Child Development \& Care, 185(5), 709-726. doi:10.1080/03004430.2014.951928 
Bowlby, J. (1953). Childcare and the growth of love. London: Penguin Books.

Bowlby, J. (1988). Attachment, communication, and the therapeutic process. A secure base: Parent-child attachment and healthy human development, 137-157

Burke, D. L. (1997). Adding Time, Strengthening Relationships. ERIC Document Reproduction Service NO. ED414098.

Chirichello, M., \& Chirichello, C. (2001). A standing ovation for looping: The critics respond. Childhood Education, 78(1), 2-9.

Creswell, J. (2013). Qualitative inquiry and research design: Choosing among five approaches. $3^{\text {rd }}$ ed. Thousand Oaks, CA: Sage Publications.

Cryer, D., Hurwitz, S., \& Wolery, M. (2001). Continuity of caregiver for infants and toddlers in center-based childcare: Report on a survey of center practices. Early Childhood Research Quarterly, 14(4), 497-514.

Dube, S.R., Felitti, V.J., Dong, M., Chapman, D.P., Giles, W.H. and Anda, R.F. (March 2003). The relation between adverse childhood experiences and adult health. Pediatrics 111 (3). 564572 .

Goldberg, S., Muir, R., \& Kerr, J. (2013). Attachment theory: Social, developmental, and clinical perspectives. Routledge.

Grant, J., \& Johnson, B. (1995). A common sense guide to multiage practices. Columbus, $\mathrm{OH}$ : Teachers' Publishing Group.

Groot Kim, S. (2010). There's Elly, It Must be Tuesday: Discontinuity in Child Care Programs and Its Impact on the Development of Peer Relationships in Young Children. Early Childhood Education Journal, 38(2), 153-164. doi:10.1007/s10643-010-0400-6

Hanson, B.J. (1995). Getting to know you: Multiyear teaching. Educational Leadership, 53(3), 42-43.

Haslinger, J., Kelly, P., \& O'Lare, L. (1996). Countering absenteeism, anonymity, and apathy. Educational Leadership, 54(1), 47-50.

Hegde, A.V. \& Cassidy, D.J. (October 2004). Teacher and parent perspectives on looping. Early Childhood Education Journal 32 (2). 133-138.

Jacobs, G. (2012). Relationships: The Heart of Early Childhood Education. YC: Young Children, 67(5), 6.

Karr-Morse, R. \& Wiley, M.S. (2012). Scared sick: The role of childhood trauma in adult disease. New York: Basic Books.

Laboratory at Brown University. (1997). Looping: Supporting Student Learning Through LongTerm Relationships. Brown University Press. Office of Educational Research and Improvement (OERI), Department of Education, under contract no. RJ96006401. Retrieved from http://www.brown.edu/academics/education-alliance/sites/brown.edu.academics.educationalliance/files/publications/looping.pdf

Journal of the Scholarship of Teaching and Learning, Vol. 17, No. 2, April 2017.

josotl.indiana.edu 
Lieberman, A.F. \& Knorr, K. (2007). The impact of trauma: A developmental framework for infancy and early childhood. Pediatric annals 36 (4). 209-215.

Miller, K. (1995). Caring for the little ones. Child Care Information Exchange, 104, 75-76.

Minkel, J. (17 June 2015). Why Looping Is a Way Underappreciated School-Improvement Initiative.EducationWeek.Retrievedfrom http://www.edweek.org/tm/articles/2015/06/17/loopinga-way-underappreciated-school-improvement-initiative.html.

Murgatroyd, C., \& Spengler, D. (2011). Epigenetics of Early Child Development. Frontiers in Psychiatry, 2, 16. http://doi.org/10.3389/fpsyt.2011.00016

National Association for the Education of Young Children. (2015). DAP with Infants and Toddlers. Retrieved from http://www.naeyc.org/dap/infants-and-toddlers

Porter, N. (2012). High turnover among early childhood educators in the United States. Retrieved from http://www.childresearch.net/projects/ecec/2012_04.html.

Scaer, R. (2005). The trauma spectrum: Hidden wounds and human resiliency. New York: W.W. Norton.

Thomas, K. A. (2014). Studying the looping cycle in early childhood public education: A multiple case study analysis (Doctoral dissertation, The University of Alabama at Birmingham).

Thomson, P. (2007). Down will come baby: Prenatal stress, primitive defenses, and gestational dysregulation. Journal of trauma and dissociation 8 (3). 85-113.

Yin, R. K. (2013). Case study research: Design and methods. Sage Publications.

Journal of the Scholarship of Teaching and Learning, Vol. 17, No. 2, April 2017.

josotl.indiana.edu 